\title{
ASPECTOS DA ENFERMAGEM NA PROFILAXIA E TRATA- MENTO DA DOENÇA DE CHAGAS, DA MALÁRIA E DA ESQUITOSSOMOSE *
}

\begin{tabular}{l|l|}
\cline { 2 - 2 } & RBEn/04 \\
\hline
\end{tabular}

GODOY, I. L. - Aspectos da enfermagem na profilaxia e tratamento da doença de chagas, da malária e da esquistossomose. Rev. Bras. Enf.; DF, 33 : 166-172, 1980.

\section{1 - INTRODUÇĀO}

Os avanços modernos tecnológicos e o desenvolvimento constante das ciências proporcionam medidas cada vez mais eficazes para o controle, a prevenção e o tratamento das doenças. A despeito dos consideráveis progressos obtidos no controle das doenças transmissíveis, ainda constitui problema de saúde pública a situação atual das grandes endemias no Brasil, por dificuldades de ordem operacional, cultural, econômica e social.

Das grandes endemias parasitárias, grandes pela sua natural tendência a se expandir por extensos espaços do território nacionąl, pela gravidade da sua agressão ao organismo do homem e pela repercussão que têm sobre o desenvolvimento humano, três delas merecem especial destaque: a doença de Cha- gas, a malária e a esquistossomose, que justificadamente, ocuparão maior tempo e mais largo espaço para a análise do seu comportamento epidemiológico e para que se reavive o conhecimento dos meios que se vem utilizando no seu combate.

Com providências atualmente em curso contra as grandes endemias, o Ministério da Saúde vem assinalando, de forma cada vez mais objetiva e dinâmica, a sua presença na zona rural brasileira mediante o trabalho sequiencial de suas estruturas organizacionais e operativas e na execução dos programas especiais de controle das endemlas confiada a órgãos desse Ministério, estruturados especificamente para esse fim.

O pessoal de enfermagem, como integrante das equipes de saúde que atuam em todos os níveis da estrutura

- Trabalho apresentado no XXI Congresso Brasileiro de Pediatria - Brasilla, de 6 a 12 de outubro de 1979.

* Autora e relatora - Supervisora de Enfermagem da Representaçåo da FSESP Brasilia-DF. 
GODOY, I. L. - Aspectos da enfermagem na profilaxia e tratamento da doença de chagas, da malária e da esquistossomose. Rev. Bras. Enf.; DF, 33 : 166-172, 1980.

dos serviços de saúde, tem uma importante contribuição nos programas de controle dessas endemias, principalmente no trabalho educativo junto às populações atingidas e no tratamento dos casos, bem como participando na elaboração dos referidos programas.

Na III Reunião Especial de Ministros de Saúde das Américas, em Santiago do Chile, o Brasil apresentou ao Plano Decenal de Saúde para as Américas - 1972/1980, um informe da situação espzcífica da enfermagem, basicamente relacionada a três áreas de necessidades: a) disponibilidade de ações de enfermagem em número suficiente para atingir uma cobertura útil aos grupos vulneráveis, especialmente os situados nas áreas suburbanas e rurais; b) equilíbrio dos recursos hu.nanos de enfermagem em quantidade, qualidade e distribuiçãa; c) eficiência e rendimento desses recursos humanos mediante a racionalização das estruturas organizacionais, apoladas em estudos e pesquisas especificas.

A enfermagem da América Latina e da área do Caribe assumiu perante o referido Plano o compromisso de tentar solucionar parte das deficiências apontadas de modo a: a) proporcionar assistência de enfermagem a pacientes em $60 \%$ dos serviços de saúde da comunidade e em $60 \%$ dos hospitais de 100 leitos e mais; b) ampliar a assistência de enfermagem materno-infantil, a fim de cobrir maior proporção dos grupos vulneráveis; c) obter uma força de trabalho ativa que represente uma proporção de 19 elementos de pessoal de enfermagem para cada 10.000 habitantes, dos quais 4,5 por 10.000 deverão ser enfermeiras; d) intensificar a capacitação de pessoal de enfermagem, visando preparar, até o final do decênio, 124.917 enfermeiras e 360.000 auxiliares de enfermagem.

A enfermagem moderna iniciou-se no Brasil com caráter de enfermagem de saúde pública, há aproximadamente cinqüenta anos.

Terminada a I Grande Guerra, persistia no Brasil a luta contra a terrível epidemia de 1918. As medidas curativas eram ineficientes porque ineficientes haviam sido até então as medidas preventivas, incluindo o saneamento básico e a educação para a saúde. A reorganização da Saúde Pública em 1920, no Rio de Janeiro, fez sentir a necessidade de um profissional capaz de continuar, em domicílio, o trabalho de educação para a saúde, começado nos ambulatórios pelos médicos. Carlos Chagas, nome que não podemos deixar de evocar quando mencionamos a enfermagem no Brasil, então Diretor do Departamento Nacional de Saúde Pública, lembrou-se da enfermeira como elemento integrante da equipe sanitária, conforme já ocorria nos Estados Unidos da América do Norte. Para o propósito mencionado, em nome do governo brasileiro, dirigiu-se à Fundação Rockfeller solicitando-lhe cooperação para a fundação de uma escola de enfermagem, em cujo ensino fosse dada ênfase à Saúde Pública. Desta iniciativa nasce, em 1923, a Escola Ana Neri.

No momento atual a enfermeira, consciente dos problemas de saúde do país, participa da equipe multiprofissional na elaboração de planos para solução desses problemas, sendo capaz de atuar num sistema político sócioeconômico em constante mutação e de delegar certas tarefas ao pessoal auxiliar de enfermagem, objetivando a ampliação de suas atividades no campo da saúde.

\section{ASPECTOS GERAIS DAS ENDEMIAS CONSIDERADAS}

\subsection{Doença de Chagas}

A endemia chagásica acha-se amplamente disseminada no território na- 
GODOY, I. L. - Aspectos da enfermagem na profilaxia e tratamento da doença de chagas, da malária e da esquistossomose. Rev. Bras. Enf.; DF, 33 : 166-172, 1980.

cional, em conseqüência do tipo de habitação geralmente usado no interior do país, feita de barro e construída de paua-pique, não rebocada e com teto de palha, o que favorece a colonização dos "barbeiros" transmissores, possibilitendo a persistência do ciclo domíciliar da doença.

Essas condições básicas para a transmissão da doença por si só indicam que a endemia é característica das áreas rurais mais pobres e de baixo nível sócio-econômico, o que vale dizer que, pelas mesmas razões, ela vem se expandindo por extensas faixas interioranas desde que encontre vetores eficazes ao nível domiciliar. Trata-se pois de uma endemia expansiva

A presença de vetores domiciliares da doença já foi comprovada desde o Rio Grande do Sul até o Ceará. Inquéritos entomológicos e sorológicos revelaram que os focos de maior endemicidade estão localizados nos Estados de Minas Gerais, Golás, São Paulo, Paraná, Rio Grande do Sul, Alagoas e Pernambuco.

Os intensos movimentos migratórios para abertura e incorporação de novas áreas à economia nacional constituem fatores de disseminação da endemia.

A inexistência de qualquer recurso terapêutico específico capaz de atingir - agente causal, representa papel da maior importância na propagação da doença e na sua alta morbidade e mortalidade. Na criança menor de 2 anos, a doença de Chagas é geralmente letal, em conseqüência de complicações meningo-encefálicas.

A maioria dos pacientes de mais idade sobrevive à fase aguda, desaparecendo ou diminuindo os parasitos do sangue periférico. A doença, aparentemente assintomática, entra na fase crônica por vários anos, até que surjam as formas cardíaca, digestiva e nervosa.

A cardiopatia chagásica é a forma responsável, nas áreas endêmicas, pela freqüência de morte súbita em pessoas do grupo de idade entre 25 a 50 anos, faixa etária de maior produtividade.

Com base em inquéritos sorológicos, estima-se que haja no país entre 3 e 4 milhões de indivíduos infectados pelo Tripanosoma cruzi (1). Apesar da inexistência de drogas, antibióticos ou produtos biológicos imunizantes de natureza especifica contra o Tripanosoma cruzi no organismo humano, o que torna impossível a cura do doente, cumpre ao Ministério da Saúde combater a endemia até alcançar a ruptura da cadela de transmissão, dela eliminando os transmissores intradomiciliares e impedindo o seu acesso por medidas de vigilância entomológica.

O objetivo fundamental do programa de controle da doença de Chagas é reduzir a transmissão da infecção no território nacional. Levantadas as variáveis que envolvem o problema e eqüacionando-as num contexto programático, pode-se derinir um modelo operacional a ser executado com firmeza e continuidade. o que está em curso na atual luta contra a endemia chagásica, através da SUCAM e FSESP.

Encontra-se em curso na FSESP um projeto destinado à "Melhoria da Habitação Rural" para o controle da doença de Chagas em 28 municípios de sete Estados do nordeste brasileiro, onde, além da infestação por triatomíneos, a esquistossomose é endêmica.

\subsection{MALÁRIA}

A malária ainda incide sobre extensos espaços do território nacional, sobretudo na grande Região Amazônica; entretanto, já fol erradicada nas áreas de maior significação demográfica e sócio-econômica.

O governo brasileiro vem executando, há alguns anos, uma campanha de erradicação da malária, cujo objetivo é interromper, por completo, a transmis- 
GODOY, I. L. - Aspectos da enfermagem na profilaxia e tratamento da doença de chagas, da malária e da esquistossomose. Rev. Bras. Enf.; DF, 33 : 166-172, 1980.

são da doença em todo o território nacional.

De acordo com informação da SUCAM, surtos de novos casos de malária passaram a eclodir em áreas não maláricas, motivados pelo fluxo migratório de indivíduos de outras áreas do país para as regiões Norte e CentroOeste, tendo em vista que seu reflexo pode causar a introdução ou reintrodução da endemia.

A permanência dos mosquitos transmissores nas áreas das quais a malária já foi erradicada, ou nas quais teve sua transmissão interrompida, exige a manutenção de um sistema de vigilância de alta eficiência para evitar a reintrodução da doença e sua rápida disseminação.

A SUCAM modificou a estratégia no programa de erradicação da malária no Brasil, em decorrência das caracteristicas geográficas, epidemiológicas e sócioeconômicas peculiares a cada área. Com base neste fato, a nova estratégia se baseia nos seguintes objetivos:

a) erradicação da malária a curto prazo, nas áreas em que os fenômenos ecológicos estejam estabilizados;

b) erradicação, a longo prazo, nas áreas em desenvolvimento, favorecendo a fixação do homem;

c) vigilância epidemiológica nas áreas em que a doença já fol erradicada ou teve sua transmissão interrompida, visando a impedir a reintrodução da endemia;

d) estudo das "áreas-problema" (vale amazônico, áreas com transmissão por Kerteszia).

A malária é uma doença cuja letalidade é geralmente inferior a $1 \%$. Contudo, nas crianças e adultos acometidos pela primeira vez de terçã maligna, pode chegar a $10 \%$ ou mais, nos casos não tratados.
A gestante com envolvimento malárico (3) da placenta causa o nascimento de crianças menores do que as que provêm de placentas não infectadas. As crianças procedentes de placentas maláricas podem ter reduzidas todas as dimensões do corpo e algumas placentas são anormalmente pequenas.

A malária da placenta interfere no fluxo vascular e no suprimento de nutrientes ao feto.

Os efeitos da malária sobre as crianças desnutridas mais velhas e os adultos são de interesse, particularmente na presença de desnutrição proteínica. Durante um ataque de malária, algumas células vermelhas do sangue são destruídas e o ferro é liberado. Um estudo de 110 pacientes anêmicos no Quênia revelou que a infecção bacteriana era mais comum na anemia hemolítica secundária à malária em $83 \%$ contra $7 \%$, num grupo de controle; 0 ferro liberado pelas células vermelhas hemolizadas na presença de diminuição de ferro ligado a proteínas promove o crescimento le bactérias. Também a febre alta na malária aumenta as necessidades calóricas do indivíduo.

\subsection{ESQUISTOSSOMOSE}

A esquistossomose mansônica encontra-se amplamente disseminada pelo território nacional, já tendo sido encontrada em 944 municípios de 17 unldades da Federação.

A doença ocorre em área contínua, abrangendo a faixa litorânea, a zona da mata e partes do agreste, desde o Rio Grande do Norte até o sul da Bahia, daí penetrando no nordeste de Minas Gerais. Além dessa área endêmlca contínua, há numerosos focos isolados de variável magnitude nos Estados do Pará, Maranhão, Ceará, Espírito Santo, Rio de Janeiro, São Paulo, Goiás, Distrito Federal e Paraná. 
GODOY, I.L. - Aspectos da enfermagem na profilaxia e tratamento da doença de chagas, da malária e da esquistossomose. Rev. Bras. Enf.; DF, 33 : 166-172, 1980.

Evidenciada a gravidade do acometimento humano e considerada a larga e. progressiva expansão da parasitose em causa no território nacional, seja sob a aspecto endêmico ou sob a condição focal, compreende-se como ela aflige, abate e compromete a saúde e a economia de milhares de brasileiros.

A prevalência é geralmente estimada em 7 milhões de indivíduos infectados, com elevada percentagem de formas graves em determinados focos endêmicos.

A Amazônia, com exceção dos focos paraenses, mantém-se livre da esquistossomose, o mesmo sucedendo com a maior parte do Centro-Oeste e com o Extremo Sul. Entretanto, as correntes migratórias continuam expandindo a endemia e ameaçam regiões ainda não comprometidas.

Por outro lado, o desenvolvimento do país, com a abertura de novas estradas e o desbravamento de áreas para colonização, tem criado condições ecolơgicas favoráveis à expansão geográfica da esquistossomose.

As medidas de combate à esquistossomose são representadas essencialmente pelo saneamento básico, mediante a construção de sistemas de abastecimento de água e de remoção de dejetos; tratamento dos hospedeiros intermediários portadores do Shistosoma mansoni, mediante o uso de moluscócidas, coadjuvados por obras de saneamento ou aterro e um processo educativo da coletividade com atuação integrada dos órgãos da saúde, agricultura, educação, previdência social e de desenvolvimento regional e local, ao lado da participação das instituições de comunidades presentes nas áreas-problema.

A integração de procedimentos e nova metodologia constitui o princípio da nova política de combate à esquistossomose, através de um Programa de Controle da Esquistossomose, o PECE, em plena execução a cargo da SUCAM e da FSESP, com participação integrada desses dois órgãos do Ministério com definição de atividades específicas para cada um.

A FSESP desenvolve as ações de "Saneamento Básico" nas áreas de esquistossomose endêmica, preponderantemente na zona rural e periférica dos centros urbanos, visando a afastar o homem de águas infestadas, impedindo a sua contaminação, por força dos máus hábitos e das precárias condições ambientais e educacionais.

\section{PARTICIPAÇAO DA ENFERMAGEM NO CONTROLE DAS ENDEMIAS MENCIONADAS}

A análise da situação dos Serviços de Saúde do país, revela, à exceção de alguns serviços bem estruturados, um "deficit" acentuado de pessoal de enfermagem de todos os níveis e uma utilização pouco significativa do pessoal disponivel, principalmente no desenvolvimento das ações educativas imprescindiveis ao sucesso dos programas de controle das grandes endemias.

f crescente o número de enfermeiras que se especializam nos cursos de Saúde Pública existentes no país, e que estão assim capacitadas para liderar as equipes de enfermagem que atuam no campo e participar com outros profissioaais de saúde da elaboração dos programas de controle.

A criação da Carreira de Sanitarista, em que a enfermeira é um profissional integrante, abre perspectivas para que a esse profissional seja atribuído papel no campo específico do controle das endemias que afligem 0 país.

Para uma atuação eficaz, frente à problemática pertinente a essas endemias, a enfermeira teria que atuar em conjunto com os demais sanitaristas componentes, da equipe, tendo, como base: 
GODOY, I. L. - Aspectos da enfermagem na profilaxia e tratamento da doença de chagas, da malária e da esquistossomose. Rev. Bras. Enf.; DF, 33 : 166-172, 1980.
a) distribuição geográfica da doen- ça;
b) ciclo de transmissão;
c) população em risco;
d) potencialidade endemo-epidêmi- ca;
e) morbidade;
f) letalldade;
g) conseqüências econômico-sociais;
h) disponibilidade de recursos pro- flláticos e terapêuticos eficazes;
i) viabilldade econômico-financeira do programa de controle;
j) implicações nacionais e interna- cionais.

\subsection{Ações da ENFERMagem Na Profilaxia e Tratamento}

A implementação das ações do pessoal de enfermagem na profilaxia e tratamento das citadas endemias, depende do maior ou menor grau de intensidade da doença e do nível operacional dos serviços, entretanto, deve ser centrada nas seguintes ações:

a) educação em saúde a pessoas, e grupos $^{-}$da comunidade, dando ênfase aos escolares, professores e líderes locais, sobre os aspectos inerentes às medidas de proteção individual e coletiva e da melhoria das condições de habitação e do melo ambiente;

b) investigação e vigilância epidemiológica;

c) visita domiciliar em condições especiais;

d) colheita de material para exames de laboratório;

e) ministração de tratamento prescrito ou padronizado, assim como distribuição e controle dos mesmos;

f) notificação da doença à autoridade sanitária;

g) participação no processo de recuperação em casos com seqüelas, em especial no tocante à doença de Chagas;

h) encaminhamento de pacientes conforme o sistema de referência;

1) participação nos programas de treinamento de Agentes de Saúde Pública para o controle dessas endemias;

j) elaboração de manuais de normas técnicas, administrativas e de procedimentos para o pessoal de enfermagem e elementos da comunidade;

k) participação, com a equipe de saúde, no planejamento, na supervisão e na avaliação das medidas de controle.

\section{REFERENCIAS BIBLIOGRAFICAS}

1. Brasll - Ministério da Saúde - Anais da VI Conferência Nacional de Saúde - 1977 .

2. Viles Boas, Aldo - Relatório da Fundaçáo SESP - 1974 - 1978.

3. Brasil - FSESP - Boletim Epidemio16́gico, Ano X, n.0 24 - Nota extraida do artigo de Neuman, Charlotte G., Jellife, Derrick, B. e Pa- trice Jelliffe, E. F. Interaction of Nutrition and Infection - Clinical Pediatrics - 11: 807-812 1978.

4. Brasil - Ministério da Saúde - Campanha Contra a Doença de Chagas - 1973.

5. Brasil - Ministério da Saúde - Saneamento Básico em Áreas de Esquistossomose Endêmica - 1976. 
GODOY, I. L. - Aspectos da enfermagem na profilaxía e tratamento da doença de ch:gas, da malária e da esquistossomose. Rev. Bras. Enf.; DF, 33 : 166-172, 1980.

6. M. Minter, Donald - "Efectos de La Presencia de Animales Domésticos en Viviendas Infestadas Sobre La Transmision de La Enfermidad de Chagas al Hombre". Boletin de La Oficina Sanitaria Panamericana Vol. LXXXIV, N..$^{4}$ - Abril 1978.

7. Brasil - Ministério da Saúde - OPS/ OMS - Padrões Mínimos de Assistência de Enfermagem à Comunidade - 1978.

8. OPS/OMS - "Sistemas de Vigilância Epidemiológica de Las Enfermidades Transmisibles y Zoonosis". Publicaçāo Cientifica N. ${ }^{\circ} 288$ 1974.

9. Ministerio de Sanidad y Assistencia Social - "Manual Normativo $\mathrm{Pa}$ ra Auxiliares de Enfermería y Outro Personal Voluntario", Caracas - Venezuela, 1971.
10. OMS - "Problemas de Salud Previsibles Para el periodo - 1978-1983" - Cronica de La OMS - Vol. 31, n. ${ }^{\circ} 4-1977$.

11. OPS/OMS - Profilaxia das Doenças Transmissíveis - Décima Primeira Edição - 1973.

12. OPS/OMS - Plan Decenal de Salud Para Las Americas - Informe Final de la III Reunión Especial de Ministros de Salud de las Américas - Santiago, Chile - 2/9 de octubre de 1972 - Documento Oficial N. 118 - Washington.

13. Brasil - Ministério da Saúde - Um Programa de Treinamento e Açåo em Saúde e Esquistossomose Nas Escolas das Áreas do Programa Especial de Controle da Esquistossomose (PECE) - 1978. 